\title{
Analysis and strategy research on college students' interpersonal communication barriers
}

\author{
Li Na \\ Xijing University, xi`an Shaanxi, 710123, China
}

Keywords: college students, interpersonal communication, barriers, solutions

\begin{abstract}
Problems of interpersonal communication has become one of the main troubling problems of the college students. How to avoid or eliminate the psychological stress, the psychological crisis and psychological barriers caused by psychological pressure, promote psychosomatic health, adapt to the current social environment and development with a positive, normal state of mind, prevent of mental and physical diseases, strengthen the psychological health education of college students, has become the urgent needs and common concern of each college. In this article we deeply explored the definition of interpersonal communication and the influencing factors of college students' interpersonal barriers, analyzed the causes of the interpersonal communication barriers, and put forward the solving methods so as to help college students to establish good interpersonal relationships in interpersonal communication.
\end{abstract}

\section{Introduction}

With the rapid development of society, people's life rhythm is speeding up, the increasingly competition is more and more intense, interpersonal relationship is also becoming more and more complicated; Due to the rapid progress of science and technology, knowledge explosive increase, forcing people to constantly update knowledge; "Mankind has entered the emotional weight s", the idea consciousness and emotional attitude of people is complicated. As a part of modern society, college students living and learning in colleges and universities are very sensitive to the "barometer" of social psychology era. Moreover, college students as a special social group have their own special problems, such as adapting to the new learning environment and tasks, the conflict between ideal and reality, treatment and study in the relationship, the problem of contradiction in love and career choice for the future problems and so on.

\section{The causes of college students' interpersonal communication obstacles}

All kinds of problems of college students' psychological quality are related to their own stage of mental development on the one hand and also to their social environment. College students' age is generally around the age of twenty, is in the youth, in the middle of the youth is the most intense psychological change in one's life. Because of psychological development immature, emotional instability, a series of physiological, psychological and social adaptation problem faced, psychological conflict occurs frequently, such as the conflict between ideal and reality, sense and sensibility of the conflict, the conflict between independent and dependent on, the conflict between self-respect and inferiority, poor knowledge and the discrimination of the conflict between conflict, competition and stability, and so on. If these conflicts and contradictions can not get effective and reasonable solution, and over time they will form the psychological barrier, especially for the contemporary college students, in order to win in the fierce competition in the college entrance examination, it is almost all people to learn, the parents' overprotection, exam-oriented education in school, the lack of life experience make the students' psychological be fragile and weak and lack of frustration tolerance. A small setback In learning, living, making friends, falling in love, choosing a job and so on is enough to make some of them be difficult to bear, so that a mental illness, and even run away leaving, suicide appear. From environmental factors, competition intensified, the acceleration of the pace of life, make the person produces the urgency and stress of time. Personal choice opportunity of life goals becomes more. It is difficult to balance the contradiction intensified 
inner conflict and produce and anxiety. Because of changing circumstances of maladjustment and appear all kinds of confusion, puzzlement, anxiety, tension in obvious increase, the social changes brought the growing of college students psychological impact is stronger than it has ever been a time, and more complex. A variety of physiological factors, psychological and social factors intertwined is easy to cause imbalance in the development of college students' mental. People of low psychological quality natural can not adapt to high speed, high tech, high competition environment, the heavy psychological could lead to a variety of mental illness. On the objective aspect, compared with the middle school, college study, life, human relations have changed a lot.

Learning task, content and methods have changed. Students learn the basic knowledge in middle school, the learning purpose is to prepare for further study or employment; In college students learn the professional knowledge, the learning purpose is to make students into the construction of the motherland. In high school curriculum years consistent learning one of the few course in the college entrance examination, high school teachers tutoring every day. University students should have strong ability of self-study, independent thinking and problem solving. New college students often do not adapt to the change of learning life, don't know how to adapt and control the time.

The living environment has changed. Part of the freshman in high school have experience of living on campus, but most still go to school for class and live with his family after. After entering university, class became the main living environment, the dormitory is the main living areas, daily life is provided by oneself, it is really a problem for those who are normally used to depend on their parents and family. This change brought them some mental stress.

Relationship is more complicated than it in middle school. Most of the freshmen lived concentrated in their middle school, there are some small partners together since middle school. The teacher in charge follow the re-election system, meeting every day. Familiar faces, similar languages, customs, make it a familiar living environment. In the university, the people around are from different regions, their language, customs are different; Relationships between students are from bustled and intimacy to strange. It is difficult to exchange ideas. This is very unaccustomed for new students only seventeen years old, therefore, every holiday they will miss home and the old classmates, feeling loneliness.

The attitude of social work has changed. High school work and activities are carried out under the guidance of the teacher, held by minority students. In university we should pay attention to students' self management. Things in class and community activities become more and more, besides to improve their own learning, students should to do certain social work, concerned about the class construction. Freshmen often don't adapt to the life of this larger workload, they are lack of initiative, work in its place and yet don't know how to get the politics, the pressure is heavy.

\section{Overcome their interpersonal obstacles, learn to communicate with people correctly}

Students should begin to improve interpersonal communication skills consciously in entering the university. Exercise themselves from each aspect, to overcome the various aspects of psychological problems, to improve their interpersonal skills, form a good interpersonal relationship, have a good campus life, this is helpful to the future of life and work.

\section{Grasp the basic principles of interpersonal communication}

The correct communication principles include the following four aspects: the first one is the principle of equality. Equal to others is the premise of a harmonious relationship with people. Communicate with people, everyone should be treated equally, avoid unequal treating because of the reasons of family, position, experience, expertise and ability. Equal to others is to draw on and learn the perspective-taking, only to treat others equally can we get the equally treating from others. The second one is the good faith principle. Honesty is always regarded as a interpersonal basic principles. Credit demands in social life, people should hold each other sincerely good motivation and attitude, mutual understanding and trust, heavy credit, keep faith. The third one is to forgive. Tolerance is broad-minded, magnanimous, allowing people to the fundamental problem is not haggle over every ounce. Tolerance is important to coordinate the relationship between the individual and others, it helps to expand the communication space, also helps eliminate tension and 
conflict between people. The last one is the mutual principle. In the associations of people, care about each other, help each other, to enhance the understanding of each other, deepen mutual feelings, has important significance.

\section{Learning communication skills}

College students constantly adjust and change their concepts, to form a positive accurate understanding about interpersonal. Therefore, in the interpersonal communication they should do as much as possible:

Pay attention to their appearance, behavior, speech, demeanor, temperament, and code of the conduct, give each other a good first impression. The first impression has a important role in interpersonal, it has the known effect, instant effect and long-term effect, and is often based on the other side of the instrument, manners, speech, demeanor, temperament, etc. So to strengthen their self-cultivation, communicating with the spirit of good is very important;

Others is first. Focus on other's needs, interests and feelings. The topics and forms of communication should be geared to the other's side of the scope of knowledge and experience, right to their psychological needs and interests. Learn to listen, and careful and patiently listening can let the other side feel the recognition and valuable, this is a magic weapon of interpersonal communication. At the same time, pay attention to the constructive and effectiveness in talking. College students have a strong desire to do better, getting some harvest and inspiration from conversation will be a very happy thing.

\section{Practice fully, improve interpersonal skills}

College students learn the methods and skills in the classroom, but also need a lot of practice. If you don't practice all this will is a "paper". College students should often communicate with people from the school first day, exercise their ability to make other talking and to look for mutual interest topics. Also note on that don't expect too much to the object of communication, don't hope that everyone can become your bosom friend, avoid to cause psychological loss feelings. Often think perspective-taking, realize other's feelings, will understand others' feelings and behavior, thus improve their attitude.

\section{Infiltrate the psychological quality education among the various branches teaching.}

Taking psychological quality education through various branches teaching is not only the way to school psychological education implementation, but also the inevitable requirement of various branches teaching their own development. Various branches teaching process involves the extremely rich psychological education factors, because the teaching process is the social history and cultural knowledge, ethics and values for content and the dominant thought. In the process of imparting knowledge, as long as teachers pay attention to consider the psychological needs of students, arouse students' interest in learning, and dig deep inner meaning of education, the knowledge ,experience and skills that formed by human history will be able to your spiritual wealth, which are internalized into the students' ideas, the value of life and good psychological quality, and last roots on them.

\section{Open a psychological education required courses, strengthen their ability to education.}

The increase of the psychological quality can not be without the knowledge of the corresponding. Learning the psychology, sanitation, health and other aspects knowledge can help students to understand the psychological development, grasp the psychological adjustment methods, enhance the ability of self education. The effect of psychological quality education depends largely on the initiative and enthusiasm of the students' self education, depends on the level of the ability of students' self education. As a result, the psychological quality education is to pay attention to cultivate students' ability of self education.

To strengthen the construction of campus culture, create good psychological social environment for the healthy growth of college students.

College students' healthy growth cannot leave the healthy psychological social environment, the cultivation of the college students' psychological quality is dependent on the good campus culture atmosphere. School spirit is the important content of the construction of campus culture and also the important condition influencing the students' psychological development. Good school spirit will 
subtly to optimize students' psychological quality, such as the school spirit of unity and friendship is the soil among students to form the group cohesion and collective sense of honor, to keep the harmonious interpersonal relationship between people, to facilitate students communicate with each other, help each other. Rich and colorful campus cultural activities help develop students' optimistic attitude to life and health of the joyful mood. Therefore, the school should spend forces involved in the construction of campus culture, to carry out various forms of literary style and academic activities, form the environment of healthy atmosphere, loose understanding, help students to deepen self-awareness, full development of personality, to improve the ability to adapt.

\section{Conclusion}

Overcoming the obstacle of college students' interpersonal communication needs to start from the cultivation of the college students' self consciousness. School, family, social factors do caused an indelible influence on college students' interpersonal communication, but it has happened, cannot be changed. College students must seek their own learning and practice to change their interpersonal barriers. Don't have too high expectations about interpersonal communication, to participate in collective activities, communicate with more and more people outside the dormitory, broadening the communication. Communicate with experienced people, try to overcome the interpersonal obstacles. All the way will be sunshine!

\section{References}

[1] LanJing. College students' interpersonal barriers to analysis and solve strategy. Intelligence, $2012(21): 203$.

[2] WenYonghui. College students' interpersonal barriers and interpersonal skills. Teenagers study an journal (shandong province), 2007 (05) : 31-33.

[3] Xu Xiaoxia. College students' interpersonal barriers in analysis. Journal of ShanDong institute of education, 2009 (04) : 60-62.

[4] Wang Hanrong, Long Jianfei,Wang Xulang. Discuss the influence factors of college students' interpersonal communication barriers and eliminate countermeasures. Economist, 2005 (02) : pp. 100-98.

[5] WangMei. College students' dormitory interpersonal relationship of contradiction and harmonious building. Journal of SiChuan liberal arts college, 2008 (6) : 111-109.

[6] He wei, Wang Lin. Influence factors of college students' interpersonal communication obstacles and solutions. China's adult education, 2007 (23) : 73-72. 